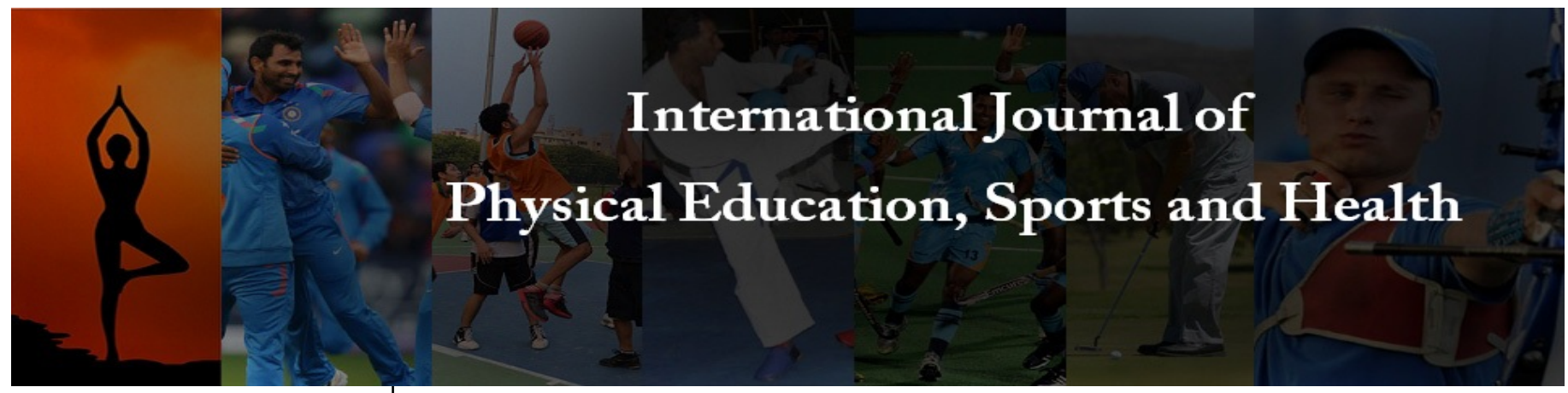

P-ISSN: 2394-1685

E-ISSN: 2394-1693

Impact Factor (ISRA): 5.38

IJPESH 2021; 8(5): 186-191

(C) 2021 IJPESH

www.kheljournal.com

Received: 24-07-2021

Accepted: 15-08-2021

Samuel Kofi Donkor

Department of Physical

Education and Sport Studies,

School of Education and

Leadership, College of

Education, University of Ghana,

Legon-Accra, Ghana

Michael Appiah

Physical Education and Sport

Unit, Department of Science,

E.P. College of Education,

Amedzofe, Ghana

Lawson Gordon Nyavor

Physical Education and Sport

Unit, Department of Science,

Akatsi College of Education,

Akatsi, Ghana

Fortune Selase Atsu

Physical Education and Sports

Unit, Department of Science,

E.P. College of Education,

Amedzofe, Ghana

ICT Unit, Department of

Mathematics and ICT E.P

College of Education, Amedzofe,

Ghana

Gibson Kwaku Avornyo

ICT Unit, Department of

Mathematics and ICT, E.P.

College of Education, Amedzofe,

Ghana

Reginald Ocansey

Professor, Department of

Physical Education and Sport

Studies, School of Education and

Leadership, College of

Education, University of Ghana,

Legon-Accra, Ghana

Corresponding Author:

Samuel Kofi Donkor

Department of Physical

Education and Sport Studies,

School of Education and

Leadership, College of

Education, University of Ghana,

Legon-Accra, Ghana

\section{Engagement in physical activity for health and well- being: Self-rated activity level, perception of the value of physical activity and differences among teachers in public primary schools of six selected educational circuits}

\author{
Samuel Kofi Donkor, Michael Appiah, Lawson Gordon Nyavor, Fortune \\ Selase Atsu, Gibson Kwaku Avornyo and Reginald Ocansey
}

DOI: https://doi.org/10.22271/kheljournal.2021.v8.i5c.2285

\section{Abstract}

Often, children draw inspiration from teachers who participate in regular physical activity for health and wellbeing. In this study, we examined 1) teachers' self-rated participation level in physical activity and perception of the value of physical activity for enhancing health and wellbeing 2) teachers' gender and class level differences in participation of physical activity and perception of the value of physical activity for enhancing health and wellbeing and 3) the correlation between teacher participation in physical activity, perception of the value of physical activity and the frequency at which physical education lessons were taught. The study adopted a cross-sectional survey with a sample of 172 subjects out of estimated population of 300 in six randomly sampled educational circuits in the Volta Region, Ghana. Self-structured questionnaire was validated by means of expert opinion and was found dependable for data collection. Pre-data analyses were performed to screen and clean data from probable errors. Data analyses were performed using Statistical Package for Social Sciences (SPSS for Windows, Version 17). The study found that the extent to which most public primary school teachers participated in physical activity was generally low. To great extent, teachers perceived positively the value of physical activity for enhancing health and wellbeing. The study did not show statistically significant differences in gender and class level participation of teachers in regular physical activity and perceptions of the value of physical activity for enhancing health and wellbeing. Positive correlation was found between teachers' participation in regular physical activity and the frequency at which physical education lessons were taught in public primary schools.

Keywords: Physical activity, physical education programme, public primary schools

\section{Introduction}

To be able to teach a variety of physical activities (PAs) prescribed in the school curriculum, it is incumbent upon physical educators to possess an acceptable standard of motor ability and considerable knowledge of subject matter in physical education (PE) content. As a school subject, PE is strenuous and demands that teachers of PE programme be in good physical and mental condition in order to carry out their instructional duties efficiently and effectively. The school PE programme should be seen as an opportunity for children to participate in meaningful physical activity (PA) for development of health and wellbeing. Accentuating to the many benefits of PA, it is noted that PA is effective for preventing and treating heart disease, diabetes and cancers (Power et al. 2019; WHO, 2018) ${ }^{[14]}$. According to literature, PA reduces symptoms of depression and anxiety (Basso \& Suzuki, 2017) ${ }^{[2]}$ and has positive effect on immunity (Campbell, 2018; Hojman, 2017; Jones \& Davidson, 2019; Miles et al., 2019) [4, 6, 19] Despite the many benefits of PA, efforts to promote active lifestyles are minimal (Reis et al., 2016) ${ }^{[13]}$. Unfortunately, global progress to increase PA has been low due to lack of awareness and investment (WHO, 2019). This situation calls for public health strategy to increase opportunities for people to be physically active for health and wellbeing in order to prevent onset of risk factors that may lead to premature death. 
Physical educators need to build healthy bodies and minds and are often expected by students, community, and management to be role models in championing PA programmes. The $\mathrm{PE}$ curriculum at the pre-school through primary school level is mainly composed of practical lessons. Therefore, professionals or individuals who teach PE at the primary school level must possess qualifications and special training skills needed to work in a variety of PAs in school setting. Fundamentally, regular participation in meaningful PA is critical to developing an active and healthy lifestyle that has the potential to prevent many health problems among general population.

Notably, perceptions influence expectations and interests of people. While positive perceptions largely encourage interest, negative perceptions tend to discourage interest. With this understanding, perceptions relating to PA may positively or negatively affect peoples' participation in regular PA for health and wellbeing. However, conscious effort by physical educators to participate in PAs often develops from initial enjoyment that is derived from the activity coupled with the requisite skills needed for participation. Teachers should be able to make use of pedagogical skills and knowledge acquired in $\mathrm{PE}$ to engage in regular $\mathrm{PA}$ outside of the $\mathrm{PE}$ classes they teach. Regular participation in PA enhances the physical and psychological health of the body, social opportunities and relationships, and quality of life. Undoubtedly, teachers are more likely to participate in PAs if they create opportunities and develop interests that are personally meaningful to them. To reap the benefits from PA participation, a certain level of personal commitment and earnest work is required by teachers.

\section{Research Questions}

The following questions were addressed:

1. What is teachers' self-rating of physical activity participation level and perception of the value of physical activity for enhancing health and wellbeing?

2. Are there significant differences between male and female public primary school teachers in physical activity participation level and perception of the value of physical activity for enhancing health and wellbeing?

3. Are there significant differences between upper and lower public primary school teachers in physical activity participation level and perception of the value of physical activity for enhancing health and wellbeing?

4. What is the relationship between public primary school teachers' participation level in physical activity, perception of the value of physical activity and the frequency of PE lessons?

\section{Methods \\ Research Design}

The study adopted cross-sectional descriptive survey to investigate a sample of teachers from six selected educational circuits in the Volta Region of Ghana. The use of crosssectional descriptive survey as a design was chosen because the study involved data gathering at a single point in time from a sample of teachers. Employing cross-sectional design for the study enabled data to be collected speedily and cost effectively from a sample of trained teachers spread over relatively wide geographical area.

\section{Population}

Notably, the ages of study participants ranged from a minimum of 21 to a maximum of 57 years with the mean age of 33.33. By gender analysis, the majority of target population were males $(n=183,61 \%)$. Females $(n=117)$ formed $39 \%$ of the target population in the study area. All subjects for the study were employees of Ghana Education Service (GES) who could read, write and speak English language.

\section{Sampling}

Sampling of study participants was conducted in stages. This was necessary in order to sample subjects from all the three distinctive geographical areas within the study area. To begin the sampling process, three geographical areas (northern, central and southern) were stratified. In the northern stratum (Kadjebi district), two out of eight circuits were randomly selected. In the Central stratum (Ho west district), two out of 13 circuits were randomly selected. In the southern stratum (Akatsi north), two out of six circuits were randomly selected. In the last stage of the sampling process, total population sampling was used to achieve a representative sample of 172 out of 300 estimated subjects in the study area. Total population sampling was employed because only 6 classroom teachers were estimated to be in each public primary school. Moreover, circuits selected for the study were composed of only six to 13 public primary schools.

\section{Instrumentation}

The instrument for data collection was self-structured. Subjects were asked to rate their level of participation in PA and their perception of the value of PA for enhancing health. Using the data collection instrument, subjects were also requested to rate the frequency at which they taught PE lessons in public primary schools. For self-rated participation in PAs and perception of the value of physical activity for enhancing health and wellbeing, descriptors on the 4-point scale were: very low extent $=1$, low extent $=2$, great extent $=$ 3 , and very great extent $=4$. However, the frequency at which PE programme was taught in the public primary schools was rated with descriptors: never $=1$, occasionally $=2$, sometimes $=$ 3 , often $=4$, and always $=5$. Expert opinion revealed that the data collection instrument was valid for collecting data for the study. Additionally, Cronbach alpha reliability coefficient revealed a good reliability of the instrument $(a \geq .71)$.

\section{Data Collection Procedures}

As part of the data collection procedures, application for ethical clearance was granted by the Institutional Review Board (IRB), University of Cape Coast in Ghana. The ethical clearance for the study was numbered UCCIRB/CES/2016/14. In addition, introduction letter was obtained from the head of department of Health, Physical Education and Recreation, University of Cape Coast. Four research assistants received orientation involving data administration, collection and management procedures. Study participants also received briefing on the purpose of data collection and were encouraged to complete the questionnaire independently as there were no wrong answers to questions answered honestly. Respondents were allowed to complete the items either in the house or during first and second breaks to avoid interference with instructional hours and submit them to data collection coordinators (school heads or designated teachers) within one week of administration. This arrangement promoted high return rate of the completed questionnaire. In all, 172 subjects correctly filled the questionnaire which was used in the analyses. 


\section{Data Analyses}

Statistical Package for Social Sciences (SPSS for Windows, Version 17) was used to analyze all data. Pre-data analyses were performed to clean data from errors. Boxplots and histograms were generated and visually inspected to ensure that variables did not violate parametric assumptions relating to the use of t-test and Pearson moment correlation coefficient involved in the data analyses. Based on a 4-point rating scale, teachers were requested to rate the extent to which they regularly participated in PA and their perception of the value of PA for enhancing health and wellbeing. Precisely, graphical presentation of analyzed data was used to determine teachers' self-rated participation levels in PA and perception of the value of physical activity for enhancing health and wellbeing. Independent samples t-test was utilized to examine gender and class level participation of teachers in PA and perception of the value of PA for enhancing health and wellbeing. Pearson moment correlation coefficient was used to explore the relationship between teachers' PA participation level, teachers' perception of the value of PA for enhancing health and frequency of PE lessons in a typical school week.

\section{Results}

Analyses of Demographic Characteristics of Subjects

Demographic data relating to gender showed that male teachers $(\mathrm{n}=97)$ who participated in the study were $56 \%$, while female teachers $(n=75)$ were $44 \%$. Figure 1 displays gender composition of subjects involved in the study.

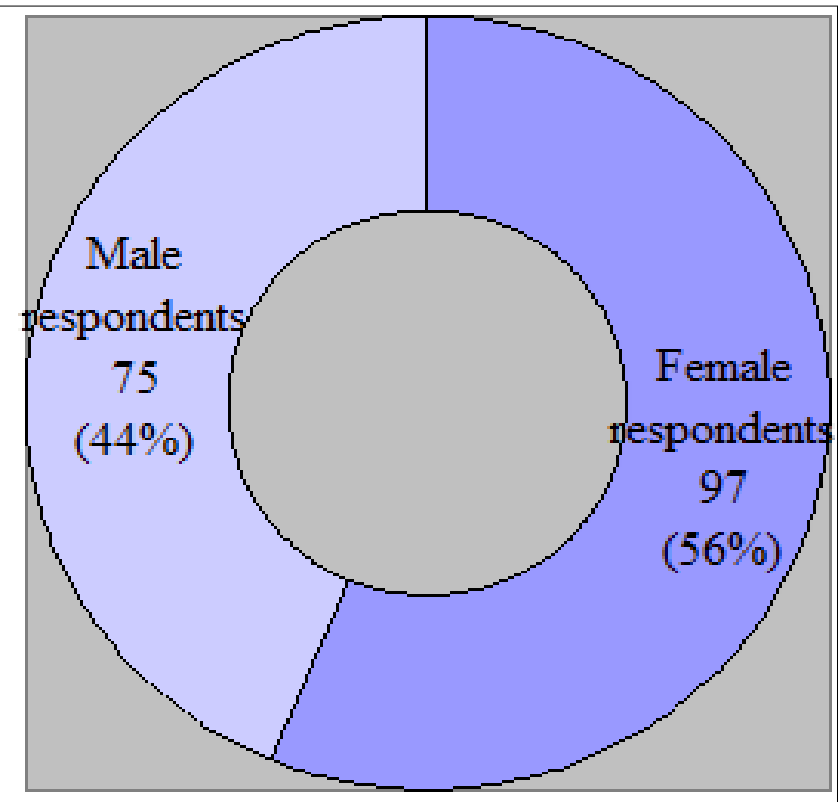

Fig 1: Gender composition of subjects

In terms of age distribution, $38 \%$ of the respondents $(n=66)$ were aged 29 years or less, $29 \%$ of the respondents $(n=50)$ were aged $30-34$ years, while $33 \%$ of the respondents $(n=56)$ were aged 35 years or more. Table 1 presents analysis of age distribution of subjects.

Table 1: Analysis of age distribution of subjects

\begin{tabular}{|c|c|}
\hline Age category & Frequency \& Percentage \\
\hline$\leq 29.00$ & $66(38 \%)$ \\
\hline $30.00-34.00$ & $50(29 \%)$ \\
\hline$\geq 35.00$ & $56(33 \%)$ \\
\hline Total & $172(100 \%)$ \\
\hline
\end{tabular}

According to the data set, out of 172 study participants, basic two teachers $(n=28,16 \%)$ were the least number of teachers who participated in the study, while basic five teachers $(n=34$,
20\%) were the most. Table two presents demographic analysis of data based on the number of class teachers who participated in the study.

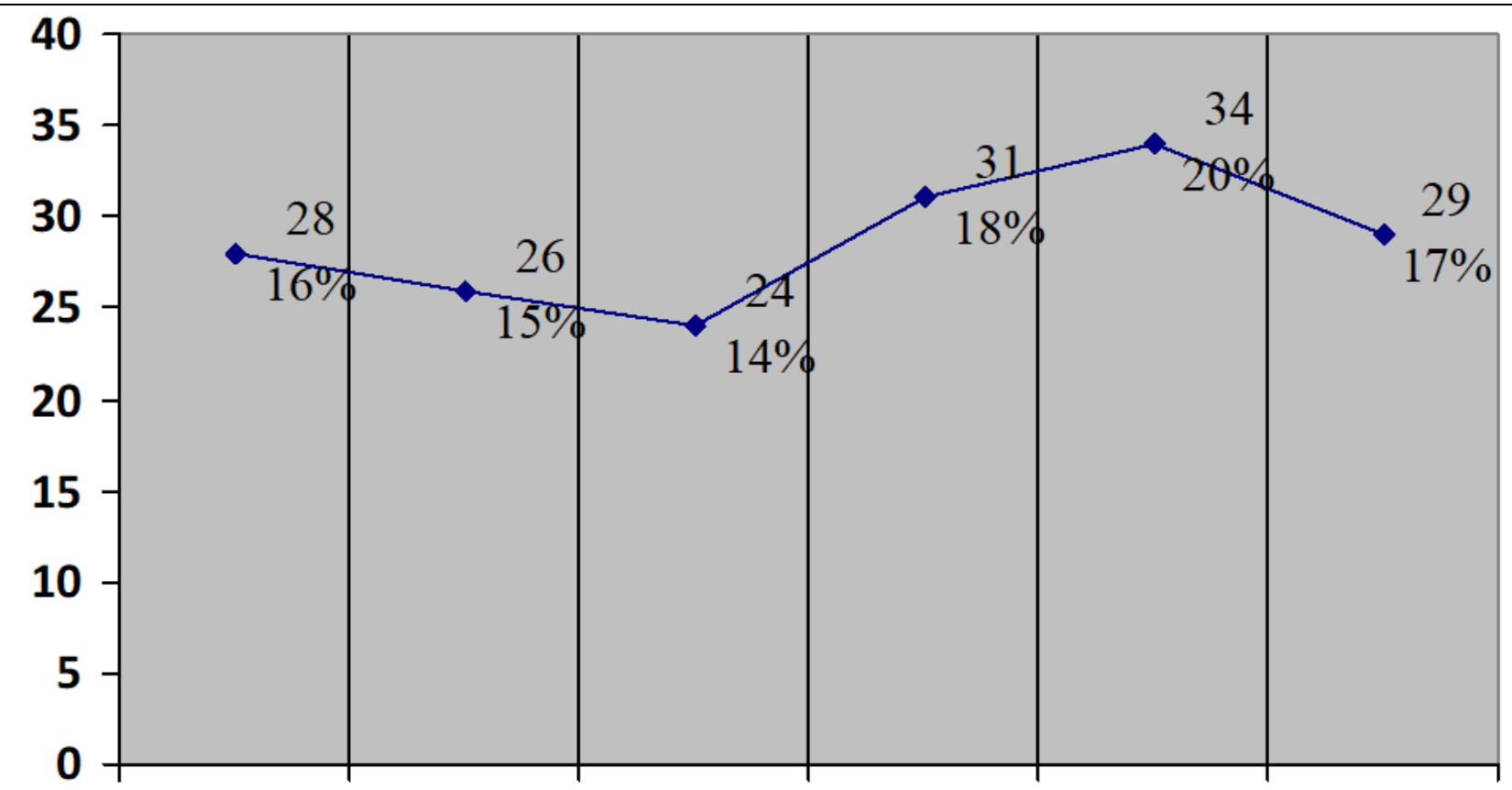

Basic one Basic two Basic three Basic four Basic five Basic six

Fig 2: Analysis of class teachers involved in the study. 
Self-Rated Participation Level in PA and Perception of the Value of PA for Enhancing Health and Wellbeing

A graphical presentation of data showed that the extent of participation in regular PA was very low for 33 subjects (19\%), low for 60 subjects (35\%), great for 58 subjects (34\%) and very great for 21 subjects (12\%). Figure 3 presents the results of self-rated participation levels of public primary school teachers in physical activities. Additionally, data relating to the perception of the value of PA for enhancing health and wellbeing revealed that seven teachers (4\%) and 37 teachers (22\%) valued PA to very low extent and low extent respectively; while 71 teachers (41\%) and 57 teachers (33\%) valued PA to great extent and very great extent. Figure 3 contains the results of public primary school teachers' perception of the value of $\mathrm{PA}$ for enhancing health and wellbeing.

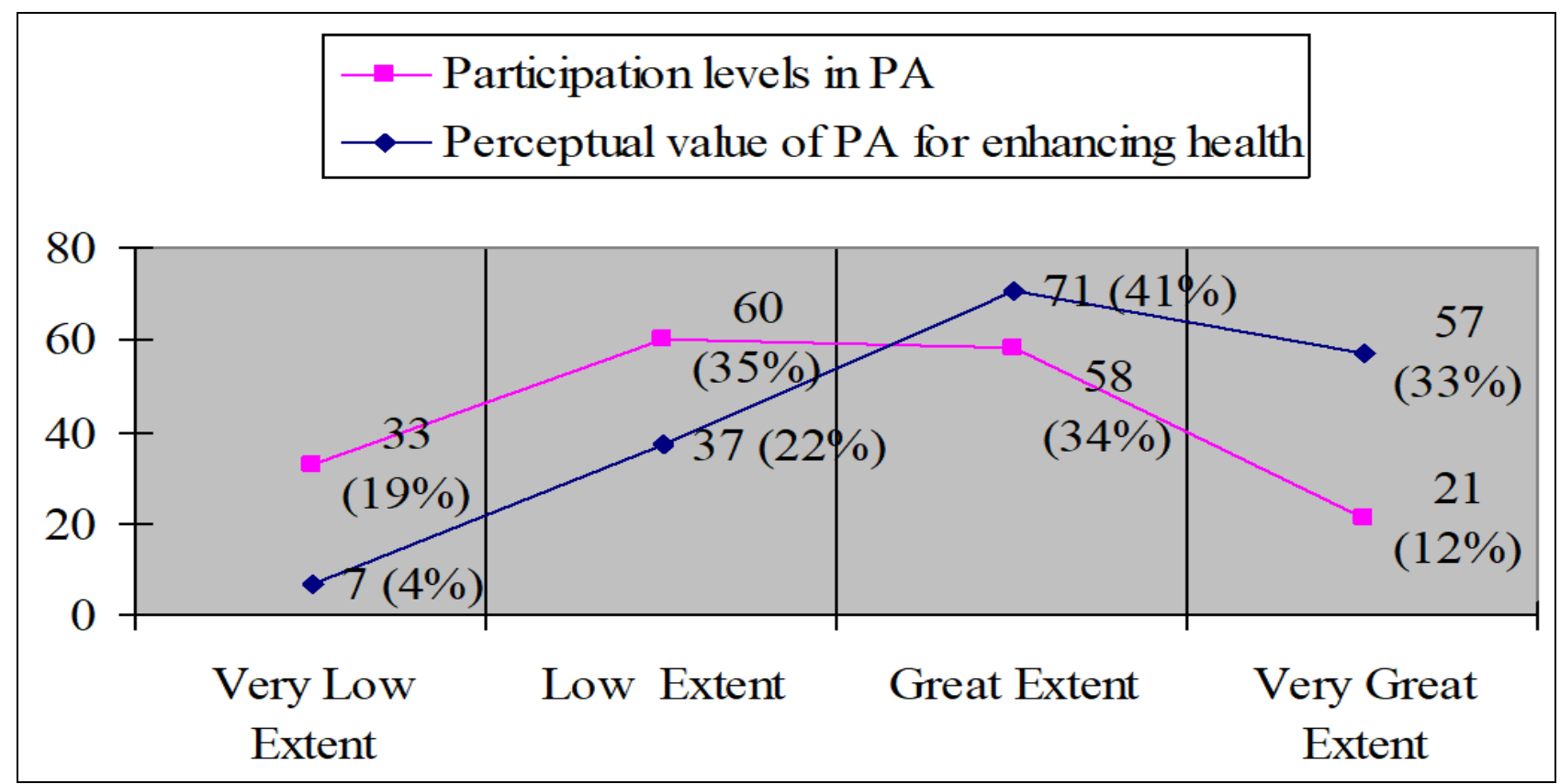

Fig 3: Participation levels in physical activity and perception of the value of physical activity for enhancing health and wellbeing among public primary school teachers

Differences between Male and Female Public Primary School Teachers in Physical Activity Participation Level and Perception of the Value of Physical Activity for Enhancing Health and Wellbeing

An independent samples t-test was performed to ascertain if there were differences in self-rated PA participation levels between male and female public primary school teachers in the six selected educational circuits. The results suggested that the difference between male teachers $(\mathrm{M}=2.48, \mathrm{SD}=0.88)$ and female teachers $(\mathrm{M}=2.27, \mathrm{SD}=0.99)$ was not statistically significant $[\mathrm{t}(170)=1.52, \mathrm{P}=.13]$. Table 2 presents the results of the differences in physical activity participation level between male and female public primary school teachers. Similarly, t-test results revealed that there was no statistically significant difference between male teachers $(M=3.03$, $\mathrm{SD}=.82)$ and female teachers $(\mathrm{M}=3.04, \mathrm{SD}=.88) ; \mathrm{t}(170)=-.07$, $\mathrm{P}=.95)$ in how the perceived $\mathrm{PA}$ as important for enhancing health and wellbeing. Table 2 presents the results of the differences between male and female public primary school teachers in their perception of the value of PA for enhancing health and wellbeing.

Table 2: Differences between male and female public primary school teachers in physical activity participation level and perception of the value of physical activity for enhancing health and wellbeing

\begin{tabular}{|c|c|c|c|c|c|c|c|}
\hline & Gender & $\mathbf{N}$ & Mean & SD & t-value & Df & p-value \\
\hline & Male teachers & 97 & 2.48 & .88 & & & \\
\hline Physical Activity Participation & & & & & 1.52 & 170 & .13 \\
\hline & Female teachers & 75 & 2.27 & .99 & & & \\
\hline & Male teachers & 97 & 3.03 & .82 & & & \\
\hline Perceptual value of PA & & & & & -.07 & 170 & .95 \\
\hline & Female teachers & 75 & 3.04 & .88 & & & \\
\hline
\end{tabular}

Significant at .05 level (2 tailed)

Differences between Lower and Upper Primary School Teachers in Physical Activity Participation Level and Perception of the Value of Physical Activity for Enhancing Health and Wellbeing

Using independent samples t-test, differences in PA participation level and perception of the value of physical activity for enhancing health and wellbeing were investigated between teachers in upper and lower public primary schools. The result revealed that the difference between upper primary school teachers $(2.4 \pm .91)$ and lower primary school teachers $(2.37 \pm 97)$ was not statistically significant $[\mathrm{t}(170)=.25, \mathrm{p}=.80]$. Table 3 presents results on the differences between upper and lower public primary school teachers in terms of participation levels in PA. Similarly, independent samples t-test was used to examine differences between teachers in upper and lower public primary schools in terms of their perception of the value of PA for enhancing health and wellbeing. Statistically, upper primary school teachers $(\mathrm{M}=3.12, \mathrm{SD}=.79)$ and lower 
primary school teachers $(\mathrm{M}=2.94, \mathrm{SD}=.90)$ were not significantly different in their perceptions of the value of PA $[\mathrm{t}(170)=1.42, \mathrm{p}=.16]$. Table 3 presents results of the differences between upper and lower public primary school teachers in their perceptions of the value of PA for enhancing health and wellbeing.

Table 3: Differences between upper and lower primary school teachers in terms of participation level in physical activities and perceptions of the value of physical activity for enhancing health and wellbeing

\begin{tabular}{|c|c|c|c|c|c|c|c|}
\hline & Primary Sch. Level & $\mathbf{N}$ & Mean & SD & t-value & Df & P-Value \\
\hline \multirow{2}{*}{$\begin{array}{c}\text { Physical Activity } \\
\text { Participation }\end{array}$} & Upper & 91 & 2.41 & .91 & \multirow{2}{*}{.25} & \multirow{2}{*}{170} & \multirow{2}{*}{.80} \\
\cline { 2 - 8 } & Lower & 81 & 2.37 & .97 & & & \\
\hline Perception of the value of PE & Upper & 91 & 3.12 & .79 & 1.42 & 170 & .16 \\
\hline & Lower & 81 & 2.94 & .90 & & & \\
\hline
\end{tabular}

Significant at .05 level (2 tailed)

\section{Relationship between physical activity participation level, perception of the value of physical activity and the frequency at which PE lessons were taught}

Pearson product-moment correlation coefficient was conducted to assess the relationship between PA participation level, perception of the value of PA and the frequency at which PE lessons were taught by teachers in public primary schools. Undoubtedly, the frequency at which PE lessons were taught in public primary schools was positively related with the participation levels of teachers in PA $(r=.34, n=172$, $\mathrm{p}=.00$ ). Table 4 contains the result of the relationship between PA participation level of teachers and the frequency at which PE lessons were taught in public primary schools. Relatedly, Pearson correlation between teachers' perception of the value of PA and frequency of PE lessons in public primary schools was positive. The correlation was however small, indicating a weak correlation between variables $(\mathrm{r}=.05, \mathrm{n}=172, \mathrm{p}=.50)$. Table 4 presents the relationship between teachers' perception of the value of PA and frequency of PE lessons in public primary schools.

Table 4: Relationship between public primary school teachers' participation level in physical activity, perception of the value of physical activity and the frequency of PE lessons

\begin{tabular}{|c|c|c|}
\hline Variable & & Frequency of PE lessons \\
\hline & Pearson's r & $.34^{* *}$ \\
\hline Teacher Participation Level in PA & Sig (2-tailed) & .00 \\
\hline & $\mathrm{N}$ & 172 \\
\hline Variable & & Frequency of PE lessons \\
\hline & Pearson's r & .05 \\
\hline Perceptions of the Value of PA & Sig (2-tailed) & .50 \\
\hline & $\mathrm{N}$ & 172 \\
\hline \multirow{2}{*}{ Significant at .01 level (2 tailed) } &
\end{tabular}

\section{Discussion}

According to the study, the extent to which most public primary school teachers participated in physical activity was generally low. However, findings of the study established that teachers perceived the value of physical activity positively for enhancing health and wellbeing. The study did not show statistically significant differences in gender and class level participation in physical activity. Similarly, the study did not reveal statistically significant differences in gender and class level perception of the value of physical activity for enhancing health and wellbeing. In the study, a positive relationship was found between teachers' participation in regular physical activity, perception of the value of physical activity for enhancing health and frequency of physical education lessons in a typical school week.

As established in literature, regular engagement in physical activity has both physical and mental health benefits. Growing evidence links physical activity to fitness experiences (Pangrazi \& Beighle, 2019) ${ }^{[10]}$, prevention and treatment of noncommunicable diseases (WHO, 2019), improvement in overall health (Eyler et al., 2002), improving functioning of immunity (Campbell, 2018; Hojman, 2017, Jones \& Davidson, 2019, Miles et al., 2019) ${ }^{[4,6,19]}$ enhanced cognitive function (Basso \& Suzuki, 2017; Powell et al., 2019) ${ }^{[2,12]}$ and reduced risk of many chronic diseases (Piercy et al., 2018) ${ }^{[11]}$. In essence, obtaining health benefits of physical activity requires participation in regular physical activity over time. In this regard, physical educators must demonstrate effective self-management skills that enable them to participate in a variety of physical activities on regular basis. Generally, regular participation in physical activity enhances the physical and psychological health of individuals, social opportunities and relationships for quality of life. For these reasons, teachers should develop an awareness of the relationship between physical activity and its immediate and identifiable effects on the body.

Results from the current study reveal that there is no statistical difference between male and female teachers in physical activity participation levels. However, it is generally believed that men and women cannot equally perform the same physiological tasks involving strenuous physical exertion. Put differently, it is largely unimaginable for men and women to equally perform the same physiological tasks in many instances. Relating to physical activity participation, Wuest and Bucher (2003) ${ }^{[16]}$ document that "Inactivity is greatest among women ...” (p.7). This categorical statement by the authors indicates that physical activity levels vary by gender. There is a general consensus that participation in physical activity can offer a great deal to individuals, communities and nations.

It is crucial to note that the physical education programme at the primary school level is heavily practical oriented. According to literature, from preschool through primary school level, practical lessons in physical education programme are devoted to the teaching of skills and the performance of exercises (Karbo, Ogah \& Domfeh, 2011) ${ }^{[7]}$. This notwithstanding, the job of the teacher is to help students to find an activity that they can positively pursue (Lund \& 
Kirk, 2019) ${ }^{[8]}$. So long as Bucher and Krotee (2002) ${ }^{[3]}$ are concerned, professionals or individuals who seek to teach PE in schools and institutions need to "possess those qualifications listed for physical educators and coaches and, in addition, the special training and qualifications needed to work in the activity ...” (p. 234). As a professional quality, teachers who teach Physical Education are required to be physically active in carrying out mandatory instructional programme of imparting physically active lifestyles in their pupils. As noted by Badrunnesha (2015) ${ }^{[1]}$, teachers are key to improving the quality of education and interact directly with students in implementing the school curriculum. Therefore, to teach various curricular activities, it is helpful to possess the skills and considerable knowledge of subject matter in physical education curricular content. It is essential for physical educators to build healthy bodies and minds and be role models in the physical activities they teach.

\section{Conclusions}

Staying committed to active lifestyles has been a difficult undertaking for several people. This notwithstanding, people generally know the value of physical activity in promoting health and wellbeing. In the study, both male and female primary school teachers and both lower and upper primary school teachers do not significantly differ in terms of physical activity participation levels and perceptions of the value of physical activity for enhancing health and wellbeing.

\section{References}

1. Badrunnesha M. Improving the quality of girls' education in madrasas in Bangladesh. Washington DC: Brookings 2015.

2. Basso JC, Suzuki WA. The effects of acute exercise on mood, cognition, neurophysiology, and neurochemical pathways: A review. Brain Plasticity 2017;2(2):127-152.

3. Bucher CA, Krotee ML. Management of physical education and sports. Boston: McGraw-Hill 2002.

4. Campbell JP, Turner JE. Debunking the myth of exercise-induced immune suppression: redefining the impact of exercise on immunological health across the lifespan. Frontiers in immunology 2018;9:648.

5. Eyler AE, Wilcox S, Matson-Koffman D, Evenson KR, Sanderson B, Thompson $\mathrm{J}$ et al. Correlates of physical activity among women from diverse racial/ethnic groups. Journal of women's health \& gender-based medicine 2002;11(3):239-253.

6. Hojman P. Exercise protects from cancer through regulation of immune function and inflammation. Biochemical Society Transactions 2017;45(4):905-911.

7. Karbo J, Ogah J, Domfeh D. An introduction to physical education. Cape Coast: CCE Publications 2011.

8. Lund JL, Kirk MF. Performance-based assessment for middle and high school physical education. Champaign: Human Kinetics Publishers 2019.

9. Miles MP, Wilson S, Yeoman CJ. Physical Activity and Inflammation Phenotype Conversion. Journal of Clinical Exercise Physiology 2019;8(2):64-73.

10. Pangrazi RP, Beighle A. Dynamic physical education for elementary school children. Champaign: Human Kinetics Publishers 2019.

11. Piercy KL, Troiano RP, Ballard RM, Carlson SA, Fulton JE, Galuska DA et al. The physical activity guidelines for Americans. Jama 2018;320(19):2020-2028.

12. Powell KE, King AC, Buchner DM, Campbell WW, DiPietro L, Erickson KI et al. The scientific foundation for the physical activity guidelines for Americans. Journal of Physical Activity and Health 2018;16(1):1-11.

13. Reis RS, Salvo D, Ogilvie D, Lambert EV, Goenka S, Brownson RC. Lancet Physical Activity Series 2 Executive Committee. Scaling up physical activity interventions worldwide: stepping up to larger and smarter approaches to get people moving. The lancet 2016;388(10051):1337-1348.

14. World Health Organization. Seventy-First World Health Assembly. World Health Assembly resolution on WHO global action plan on physical activity, 2030. World Health Organization: Geneva 2018.

15. World Health Organization. Global action plan on physical activity 2018-2030: more active people for a healthier world. World Health Organization: Geneva 2019.

16. Wuest DA, Bucher CA. Foundations of physical education, exercise science, and sport. New York: McGraw-Hill 2003. 